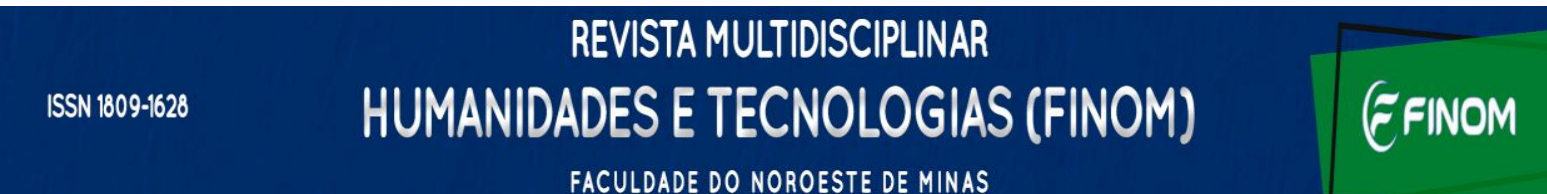

\title{
Alunos cegos desenhando e compreendendo figuras geométricas
}

\section{Blind students drawing and understanding geometric figures}

\author{
Elisabete Marcon Mello ${ }^{1}$
}

Resumo: Foi desenvolvido um estudo com dois alunos cegos, um dos alunos com cegueira adquirida no início de sua vida escolar e outro com cegueira congênita. Como o estudo com o aluno com cegueira congênita foi interrompido por conta da pandemia de COVID-19, foi relatado aqui o trabalho realizado com a aluna com cegueira adquirida. Essa aluna, que tinha memória visual, conseguiu construir figuras geométricas planas e, com a utilização de régua e compasso, retas perpendiculares, paralelas e circunferências. Foi possível observar progresso no aprendizado da aluna e constatar que, quando o cego tem a possibilidade de criar seu registro de representação no papel, ele pode se apropriar efetivamente desta representação e usá-la como uma ferramenta de apoio às suas atividades cognitivas.

Palavras-chave: Alunos cegos. Desenho. Figuras geométricas.

Abstract: A study was carried out with two blind students, one of the students with blindness acquired at the beginning of her school life and the other with congenital blindness. As the study with the student with congenital blindness was interrupted due to the COVID-19 pandemic, the work carried out only with the student with acquired blindness will be reported here. This student, who had visual memory, managed to create flat geometric figures and, with the use of a ruler and compass, perpendicular lines, parallel lines and circles. It was possible to observe progress in the student's learning and verify that, when the blind person has the possibility to create their representation record on paper, they can effectively appropriate this representation and use it as a support tool for their cognitive activities.

Keywords: Blind students. Design. Geometric figures.

\footnotetext{
${ }^{1}$ Doutora em Educação Matemática . Professora adjunta da Universidade Federal do ABC / UFABC.

E-mail: marcon.elisabete@gmail.com
}

Recebido em 23/01/2022

Aprovado em 10/02/2022

Sistema de Avaliação: Double Blind Review

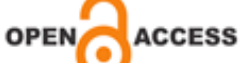




\section{REVISTA MULTIDSCIPLINAR \\ ISSN 1809-1628

\section{Introdução}

O ensino da matemática para alunos cegos requer cuidados com o uso de registros de representação, especialmente no campo da geometria, que muitas vezes exige a compreensão visual das propriedades de figuras geométricas para a resolução de problemas. Os conceitos geométricos constituem parte importante do currículo de Matemática porque, por meio deles, o aluno desenvolve um tipo especial de pensamento que lhe permite compreender, descrever e representar, de forma organizada, o mundo em que vive (BRASIL, 1998).

De acordo com Duval (2005), dentre os campos de conhecimentos que os alunos devem adquirir, a geometria é o que exige uma atividade cognitiva mais completa, pois mobiliza o gesto, a linguagem e o olhar. Para Lima (1991) o desenho de figuras geométricas é muito importante para a compreensão, fixação e imaginação criativa, sendo fundamental que o estudante desenhe a figura procurando caminhos, imaginando construções, pesquisando interconexões e exercitando a mente.

Nem sempre a importância de trabalhar esse conteúdo com alunos cegos é considerada, sendo comum, também, a falta de profissionais qualificados para esse trabalho. De acordo com a Proposta Curricular para a educação de jovens e adultos (Brasil, 2002), os conteúdos de geometria não são desenvolvidos com a devida atenção, embora contribuam decisivamente para o desenvolvimento de capacidades intelectuais como a percepção espacial, a criatividade, o raciocínio hipotético-dedutivo.

A Política Nacional de Educação Especial na Perspectiva da Educação Inclusiva (BRASIL, 2008), estabelece que os sistemas de ensino devem favorecer a promoção da aprendizagem, a valorização das diferenças e garantir educação de qualidade para todos, dando condições para que cada aluno possa desenvolver suas potencialidades. A Lei de Diretrizes e Bases da Educação Nacional (LDB, 1996), determina que a educação especial deva ser oferecida, preferencialmente, na rede regular de ensino assegurando o atendimento às necessidades desses alunos. Já a Lei Brasileira de Inclusão da Pessoa com Deficiência, de 2015, incumbe ao poder público assegurar e incentivar o acesso de pessoas com deficiência à educação superior e à educação profissional e tecnológica em igualdade de oportunidades e condições com as demais pessoas.

Nessa perspectiva, Araujo (2011) afirma que os profissionais da educação precisam assumir uma postura acadêmico-científica que leve à reinvenção da educação, pois esse 


\section{REVISTAMULTDISCPLINAR \\ ISSN 1809-1628

modelo de escola, consolidado no século XIX, tem agora que dar conta de demandas e necessidades de uma sociedade democrática, inclusiva e permeada pelas diferenças.

De acordo com Tavares, Santos e Freitas (2016) a inclusão de crianças com deficiência no contexto das escolas regulares no Brasil ainda tem muito a avançar, pois os docentes ainda não têm preparo suficiente para atuarem com crianças com deficiência de modo que haja uma inclusão efetiva. Corroborando com eles, Gatti (2009) afirma que poucos cursos de licenciatura em Pedagogia propõem disciplinas que permitam algum aprofundamento e formação de competências em relação a modalidades educacionais como educação especial, por consequência, muitos professores atuam em salas de aula inclusivas sem formação adequada.

Mello (2015) afirma que os problemas enfrentados por deficientes visuais na escola não se restringem à matemática, mas, alguns desses problemas, são agravados por características específicas desta disciplina, como por exemplo a representação dos objetos matemáticos que é um ponto crítico para os alunos que não contam com o recurso visual. Segundo Vigotsky (1997) os sujeitos cegos têm potencial para um desenvolvimento cognitivo normal, sendo necessário que os educadores busquem formas de estimular e instrumentos apropriados para que tenham acesso ao conhecimento.

Tendo em vista as dificuldades enfrentadas por alunos cegos nas aulas de matemática, foi realizada uma pesquisa ${ }^{2}$ em que se investigou como o aluno cego identifica e entende os objetos geométricos por meio de suas representações semióticas e se o fato do aluno cego ter a possibilidade de construir seus próprios registros de representação auxiliaria em seu aprendizado e em seu desenvolvimento cognitivo.

O estudo foi desenvolvido com dois alunos cegos que frequentavam as salas de aula comuns em uma escola pública do estado de São Paulo. Um dos alunos com cegueira adquirida no início de sua vida escolar e outro com cegueira congênita. Como o estudo com o aluno com cegueira congênita foi interrompido por conta da pandemia de COVID-19, será relatado aqui o trabalho realizado com o aluno com cegueira adquirida. De acordo com BOGDAN e BIKLEN (1982), essa investigação caracteriza-se como uma pesquisa qualitativa, pois busca-se a compreensão de comportamentos a partir da perspectiva dos sujeitos da investigação, em um contato direto com os indivíduos em seu ambiente escolar.

\footnotetext{
${ }^{2}$ Pesquisa aprovada pelo CEP. CAAE: 78336017.2.0000.5594. Parecer: 2.636.223
} 


\section{REVISTA MULTIDSCIPLINAR \\ ISSN 1809-1628

\section{O cego pode desenhar e compreender seu desenho?}

Duval (1999) afirma que o uso dos sistemas de representação semiótica para o raciocínio matemático é essencial, porque não há outra maneira de se ter acesso aos objetos matemáticos a não ser por meio de suas representações semióticas. Para Duval (1995), as representações não são necessárias apenas para fins de comunicação, elas são fundamentais para a atividade cognitiva, pois o funcionamento cognitivo do pensamento humano se revela inseparável da existência de uma diversidade de registros semióticos de representação.

De acordo com Borges e Clauss (2011), o desenho é uma forma de linguagem utilizada e adaptada às diferentes culturas, sendo que esta linguagem acompanha os homens desde que eram primitivos. Para as autoras a prática do desenho é muito importante para a criança e a falta dessa prática pode ser prejudicial para o seu processo de desenvolvimento e aprendizagem.

O desenho é uma forma de comunicar e representar a imagem mental referente a algum objeto ou alguma situação. Muitas vezes, para resolver problemas geométricos, adota-se a prática de fazer desenhos ou construções no papel para ajudar na organização das ideias. Será que o aluno cego poderia fazer seus próprios desenhos ou construções geométricas?

Para possibilitar ao aluno cego desenhar de forma contínua, sentindo em relevo o desenho que está fazendo, foi desenvolvido um produto denominado Prancheta de Desenho em Relevo Positiva. Trata-se de uma placa com pontos em relevo de modo que o usuário possa, por meio de uma folha de papel colocada sobre ela, imprimir os pontos em relevo, com o auxílio de um giz de cera ou um lápis de cor com ponta grossa (figura 1). Com a utilização deste produto foi realizada a investigação. 


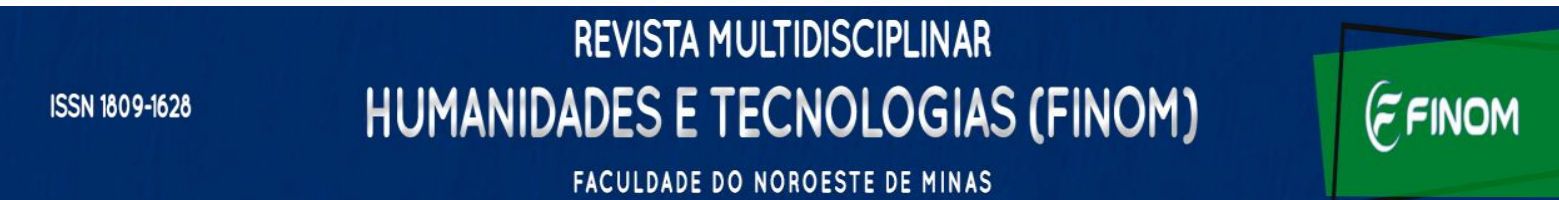

Figura 1: Prancheta de desenho em relevo positiva

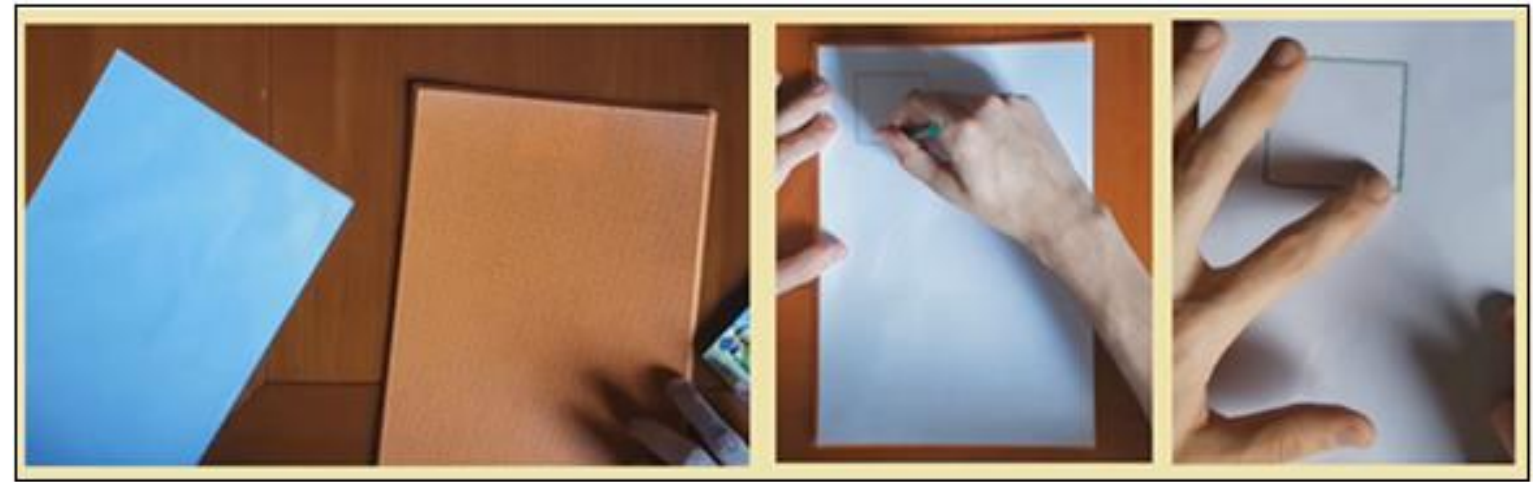

Fonte: fotos tiradas pela autora

Os resultados apresentados se referem às atividades realizadas com uma aluna do primeiro ano do Ensino Médio, com cegueira adquirida no início de sua vida escolar. O foco principal foi verificar se essa aluna poderia criar seus próprios registros de representações geométricas em relevo no papel e se isso ajudaria em seu aprendizado. A pesquisa foi desenvolvida em interação constante com a aluna, sem um roteiro rígido e as atividades foram sendo adaptadas de acordo com as respostas e o desenvolvimento da participante.

Antes de iniciar as atividades, foi constatado que a aluna tinha pouco conhecimento sobre geometria, não identificando as propriedades de objetos geométricos elementares, por exemplo, ela sabia que o quadrado tinha quatro lados, mas não sabia explicar a diferença entre um quadrado e um retângulo. Com essa constatação, foi realizado um trabalho de identificação de figuras geométricas planas e suas características.

Foi disponibilizado um tempo para que a aluna interagisse com a prancheta de desenho em relevo e pudesse aprender a usar o produto que seria seu instrumento de trabalho durante o estudo. Quando já estava familiarizada com o material, foi solicitado que, utilizando a prancheta e o lápis de cera, desenhasse figuras geométricas planas, como quadrados retângulos e triângulos (figura 2). Inicialmente teve um pouco de dificuldade para fechar as figuras, mas em pouco tempo superou esse obstáculo e conseguiu realizar a tarefa. 


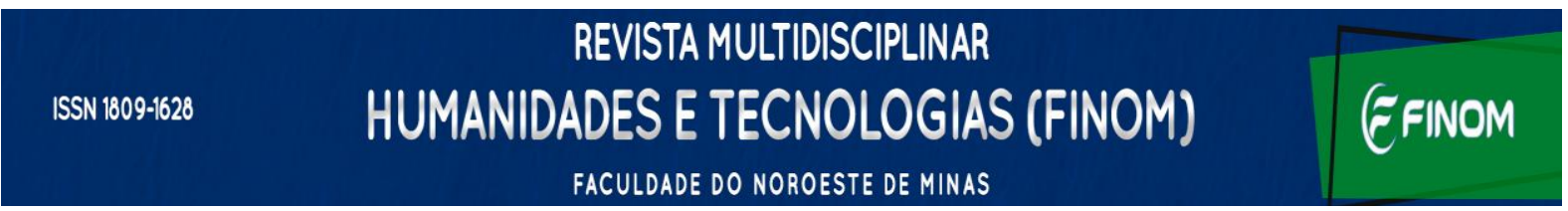

Figura 2: Desenhos feitos pela aluna cega

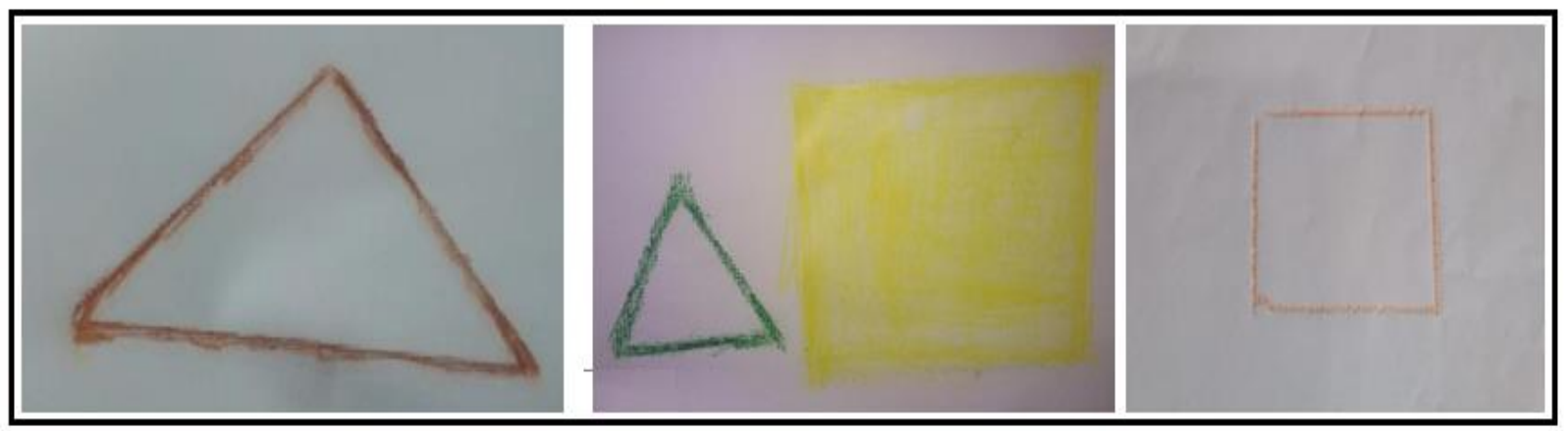

Fonte: fotos tiradas pela autora

A disposição dos pontos em relevo na prancheta auxilia na construção de uma linha reta, mesmo sem a utilização de régua, e o fato do desenho estar à tinta, além de estar em relevo, facilita a visualização do trabalho por pessoas que enxergam, facilitando essa comunicação.

Para que a aluna pudesse fazer construções geométricas utilizando régua e compasso, foi adaptada uma régua na lateral da prancheta possibilitando a utilização do esquadro e foi adaptada uma ponta de giz de cera em um compasso. Ela não teve dificuldade para utilizar um esquadro e traçar a reta horizontal, mas foi necessário ajudá-la na construção da reta vertical, pois precisava utilizar dois esquadros e ela não estava acostumada a manipular esses instrumentos. O mesmo ocorreu com a manipulação do compasso, que exigiu um período de adaptação (figura 3).

Figura 3: Aluna cega utilizando régua e compasso

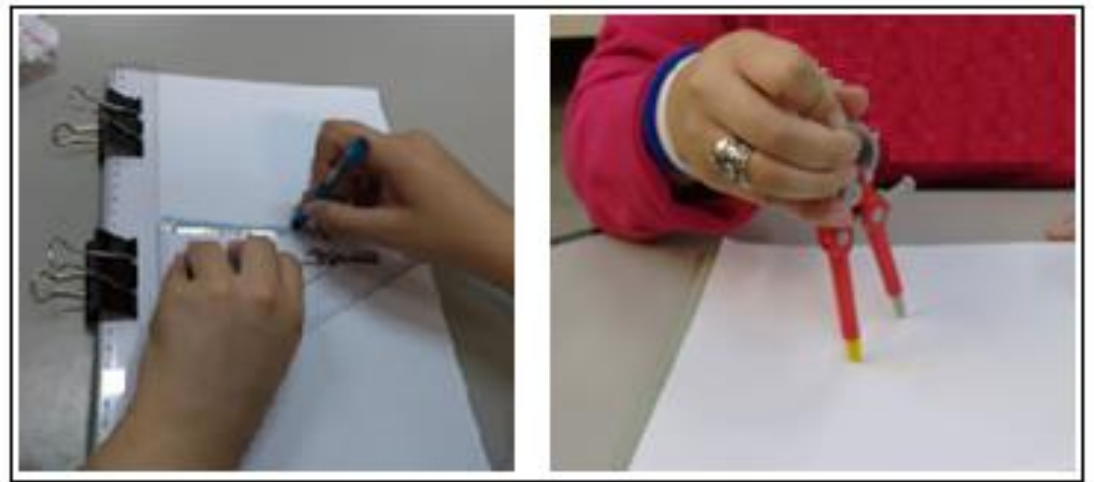

Fonte: fotos tiradas pela autora

Com esses instrumentos de construção geométrica a aluna pode construir retas paralelas e perpendiculares (figura 4), circunferências e figuras geométricas planas. A 


\section{REVISTAMULTDISCPLINAR \\ ISSN 1809-1628 \\ HUMANIDADESE TECNOLOGIAS (FINOM)}

utilização do compasso a ajudou a entender a circunferência como lugar geométrico dos pontos que equidistam de um ponto central, um conceito que era abstrato para ela e se tornou compreensível com o uso dos instrumentos.

Figura 4: Retas perpendiculares e paralelas construídas pela aluna cega

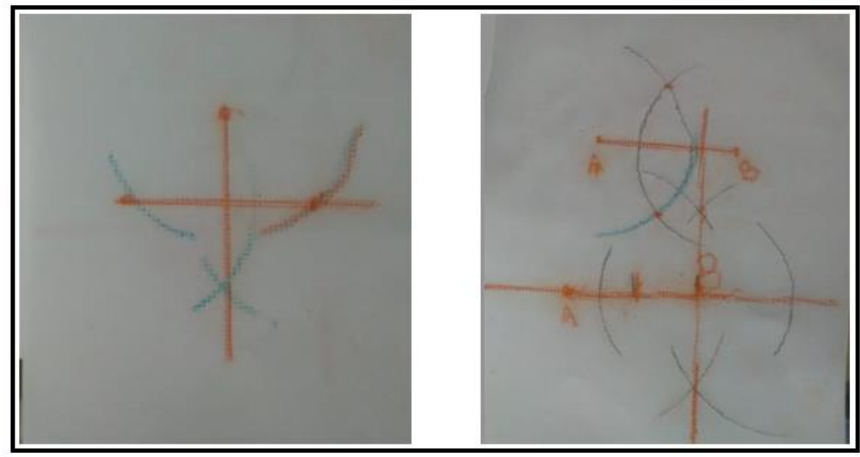

Fonte: fotos tiradas pela autora

Poder construir objetos geométricos, utilizando régua e compasso, ajudou a aluna a visualizar esses objetos e entender suas propriedades, possibilitando que ela aprimorasse seus conhecimentos e desenvolvesse novas habilidades. Isso representa um salto em seu aprendizado, pois, de acordo com Duval (1999), a representação e a visualização estão no núcleo da compreensão na matemática.

Para Duval (2005), é por meio da utilização de instrumentos de construção geométrica que os alunos podem verdadeiramente tomar consciência de que as propriedades geométricas não são somente características perceptivas. Para o autor a utilização de um instrumento dá a possibilidade de experimentar uma propriedade geométrica como uma limitação da construção. Esta constatação reforça a importância do aluno cego ter a possibilidade de realizar construções geométricas utilizando régua e compasso.

\section{Considerações finais}

Como diz Duval (1999), "ver” uma representação vai além de enxergar, é entender o que está implícito na representação, é visualizar. Durante os trabalhos foi possível observar que, mesmo sem o recurso visual, a aluna cega foi capaz de visualizar objetos geométricos e, por meio do tato, conseguiu reconhecer suas representações e características. O fato de poder fazer seu próprio desenho e criar registros de representação no papel, possibilitou que ela se 


\section{REVISTA MULTIDSCIPLINAR

apropriasse efetivamente dessas representações, podendo usá-las como ferramentas de apoio às suas atividades cognitivas. $\mathrm{O}$ desenho é uma forma importante de comunicação e foi muito gratificante ver uma aluna cega desenhando e compreendendo o que estava fazendo.

Poder sentir, em relevo, os traços que estava fazendo, foi determinante para a realização das construções geométricas. A possibilidade de desenhar foi para ela o resgate de algo que parecia impossível, e isso lhe restituiu uma autonomia que julgava perdida. Esperase que a possibilidade de desenhar em relevo no papel venha somar às formas de expressão de alunos cegos, contribuindo com sua educação e ajudando-os a superar suas limitações. Acreditamos que cada nova possibilidade apresentada a um aluno, com deficiência ou não, para desenvolver suas potencialidades, colabora para uma nova sociedade, mais justa e inclusiva.

\section{Referências}

BOGDAN, R. e BIKLEN, S. Investigação qualitativa em educação: uma introdução à teoria e aos métodos. Porto Editora, 1982.

BORGES E.S.; CLAUSS E. A importância do desenho como expressão e registro infantil. Núcleo Interdisciplinar de Pesquisa - ICESP [online]. Brasília, 2011. Disponível em: < http://nippromove.hospedagemdesites.ws/anais_simposio/arquivos_up/documentos/artigos/01 457a3ecdabb48c9d32790982e67213.pdf> Acesso em 09 dez. 2021.

BRASIL. Secretaria de Educação Fundamental. Parâmetros Curriculares Nacionais: Matemática. Brasília: MEC/SEF, 1998.

BRASIL. S.E.F. Proposta Curricular: $2^{\circ}$ segmento do E.F: 5a a 8a. Brasília: MEC/SEF, 2002.

BRASIL. Ministério da Educação. Secretaria de Educação Especial. Política nacional de educação especial na perspectiva da educação inclusiva. 2008. Disponível em: <http://portal.mec.gov.br/seesp/arquivos/pdf/politica.pdf>. Acesso em: 02 setembro de 2019.

DUVAL, R. Sémiosis et pensée humaine: Registres sémiotiques et apprentissages intellectuels. Berne: Peter Lang, 1995.

DUVAL, R. Representation, Vision and Visualization: Cognitive Functions in Mathematical Thinking. Basic issues for learning, 1999. 


\section{REVISTA MULTIDISCIPLINAR \\ ISSN 1809-1628 \\ HUMANIDADESE TECNOLOGIAS (FINOM)

DUVAL, R. Les conditions cognitives de l'apprentissage de la géométrie: Développement de la visualisation, différenciation des raisonnements et coordination de leurs fonctionnements. Annales de didactique et de sciences cognitives, vol. 10, p. 5-53, 2005.

GATTI, B. A.; BARRETTO, E. S. de S. Professores do Brasil: impasses e desafios. Brasília, DF: UNESCO, 2009.

LDB - Leis de Diretrizes e Bases da Educação Nacional. LEI Nº 9.394, de 20 de dezembro de 1996. Diário Oficial da União de 23 de dezembro de 1996.

LEI N ${ }^{\circ}$ 13.146, DE 6 DE JULHO DE 2015. Institui a Lei Brasileira de Inclusão da Pessoa com Deficiência http://www.planalto.gov.br/ccivil_03/_ato2015-2018/2015/lei/113146.htm. Acesso em: 20 de outubro de 2021.

LIMA, E. L. Medida e Forma em Geometria: comprimento, área, volume e semelhança. SBM, Belo Horizonte, 1991.98p.

MELLO, E. M. A Visualização de Objetos Geométricos por Alunos Cegos: um estudo sob a ótica de Duval. Tese (doutorado em Educação Matemática). PUC/SP, São Paulo, Brasil. 2015.

TAVARES, L. M. F. L.; Santos, L. M. M.; Freitas, M. N. C. A Educação Inclusiva: um Estudo sobre a Formação Docente. Revista Brasileira de Educação Especial, v. 22 (4), 527$542,2016$.

VIGOTSKY. L. S. Fundamentos da Defectologia. Obras Escogidas - Tomo V. Madrid: Visor, 1997. 